\title{
The Problem of Environmentally Displaced Person
}

\author{
Yanting Wei ${ }^{a,}{ }^{*}$, Yu Wang ${ }^{b}$ \\ School of Economics and Management, China University of Geosciences (Beijing), Beijing, China \\ a, *1007191202@cugb.edu.cn, b1007198114@cugb.edu.cn
}

\begin{abstract}
Global warming is accelerating the speed of sea level rise, and more and more island countries are under threat. In our essay, we build the model and develop the environmentally displaced persons allocation policy and cultural protection policy. We use the data from 43 island countries that most at risk of cultural loss to predict changes in environmentally displaced persons population. The sea level submergence model is built by simplifying complex 3D model and computer simulation. Through the model, the environmentally displaced persons population is predicted to reach 6.3 million in 100 years. Therefore, we need to combine the efforts of the international community and NGOs to help environmentally displaced persons.
\end{abstract}

\section{Keywords: Environmentally Displaced Person Tolerance Index; National Fit Degree;} Environmentally Displaced Person Distribution Index.

\section{Introduction}

\subsection{Background}

Since the 21 st century, natural disasters have swept over most countries and regions in the world. The world climate conference in Copenhagen in 2009 has captured the attention of the whole world. After the fierce competitions, all countries finally reached the Copenhagen agreement. "We stress that climate change is one of the most significant challenges we face today," the agreement said in an open-minded way However, as early as 1990, the IPCC (Intergovernmental Panel on climate change) pointed out that "one of the most serious consequences of climate change is the impact on population mobility". In other words, climate migration caused by climate change is one of the major issues that human beings need to face seriously.

At the same time, the issue of migration has always been a major concern of all countries and the international community, so climate migration should be paid more attention because of its particularity linked to climate change.

Sea level rise is one of the remarkable manifestations of the rapid change of climate and environment. Among the victims of sea-level rise, those small island countries in the Indian Ocean and the Pacific Ocean bear the brunt. For example, Maldives, Tuvalu, Kiribati and Marshall Islands. These island countries are facing the "disaster of extinction", at the same time, how to settle their own island residents has become an urgent problem for the local government.

In real life, these small island governments are constantly engaged in diplomatic and public relations, and are active in major international conferences, such as the United Nations Climate Change Conference, in order to get the attention of the international community and discuss the resettlement of island residents. And the local government represented by Tuvalu has actively sought help from neighboring countries. However, these people who are about to lose their homes have no relevant policy guarantee in terms of human rights system and cultural protection. Even those who need to leave their homes because of climate change have recently been recognized as environmentally displaced persons by the United Nations in theory.

Therefore, we should establish a model to determine the general scope of environmentally displaced persons determine how many people will be displaced due to climate problems in the future, and provide relevant policies in social, economic, human rights, legal and cultural protection for these special climate environmentally displaced persons. 


\section{Basic Assumption}

Because the impact of climate change on the world situation is very complex, it is very difficult to predict the increase of environmentally displaced persons. In order to simplify the prediction process, we only think that environmentally displaced person is the only one that has no place to go because of sea level rise and inundation of land.

Residents on the island will feel uneasy about sea level rise, and those who are very uneasy will become environmentally displaced persons. In countries such as Maldives and Tuvalu, domestic residents began to move to other countries before the established fact that the land was flooded by sea water.

Sea level higher than the original elevation of the land is considered as inundation.

Quantify the culture of the country. Take a country's geographical location, religion, eating habits, etc. as the standard to quantify the country.

\subsection{Glossary}

Environmentally displaced person tolerance index: a country's support for the acceptance of environmentally displaced persons.

National fit degree: the same degree of regional culture in two different countries.

environmentally displaced person distribution index: the proportion of environmentally displaced persons that the final selected environmentally displaced person destination country should undertake.

\subsection{Symbols}

Table 1. Definition of symbols

\begin{tabular}{|c|c|}
\hline Symbols & Definition \\
\hline$\varepsilon$ & The threat factor of sea level rise \\
\hline $\mathrm{h}$ & The dangerous height of sea level rise \\
\hline $\mathrm{k}$ & The proportionality factor of environmentally displaced persons in flooded countries \\
\hline $\mathrm{N}$ & The total number of environmentally displaced persons in the world after a certain year \\
\hline$\lambda$ & A country's acceptance of environmentally displaced persons \\
\hline$\rho$ & Population density of a country \\
\hline GDPc & per capita gross domestic product \\
\hline$\theta$ & Cultural fit index \\
\hline$\Phi$ & environmentally displaced persons' distribution index \\
\hline
\end{tabular}

\section{Models}

\subsection{Environmentally Displaced Person Prediction Model}

\subsubsection{Model Preparation}

(1) Data Processing

We collect the data of the land area, highest altitude and population of 45 island countries in the world. There are two island countries whose data are fuzzy, so we get the highest altitude and average altitude data of 43 research samples without these two countries. 
Table 2. Data of some island countries

\begin{tabular}{|c|c|c|c|c|}
\hline & & & & \\
\hline Country & Country area & Maximum altitude & Population size & Average altitude \\
\hline Bahrain & 767 & 135 & 1234571 & 45 \\
\hline Cyprus & 9251 & 1951 & 94900 & 91 \\
\hline Indonesia & 1904569 & 5030 & 266794980 & 367 \\
\hline Japan & 377972 & 3776 & 127185332 & 438 \\
\hline Maldives & 90000 & 2 & 444259 & 1.2 \\
\hline Philippines & 299700 & 2954 & 106512074 & 448 \\
\hline Timor-Leste & 14874 & 2963 & 1324094 & 988 \\
\hline
\end{tabular}

(2) Assumptions

1. Because of the impact of climate change, the population growth of island countries has been zero for quite a long time.

2. Because the factors that affect the rate of sea-level rise are very complex, the accuracy of existing data to predict sea-level rise is low. Therefore, the rate of sea level rise will remain unchanged in the future. And the rate of sea level rise is the same for all sea surfaces.

3. Because the factors that affect the fluctuation of the sea tide are very complex, the fluctuation of the sea tide is not considered.

4. People threatened by sea level will become climate environmentally displaced persons.

5. After a part of a country is submerged by sea water, the political, economic and social consequences will make the whole country collapse and all the people become climate environmentally displaced persons.

6. Although most of the island countries are composed of many islands, for the convenience of analysis, we regard each island country as a whole island.

\subsubsection{Model Establishment}

Because the topography of all the islands in the world is very different, it is difficult to accurately estimate the impact of sea water rise on each island, but there are some objective data for each island, such as the highest altitude, national area, and population. We can think of an island country as a cone. Like this:
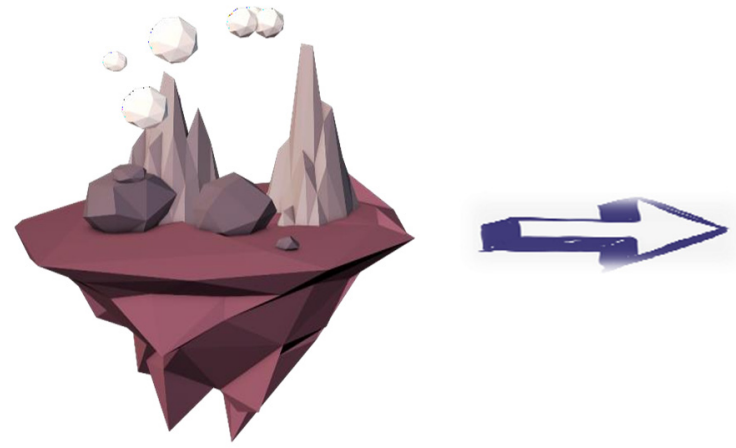

Figure 1. Simplified map of island topography

The model will calculate the corresponding Island cone size through the land area (s) of one country and the highest altitude $(\mathrm{H})$ of the whole country. 
When we regard the ground radius of the island as $\mathrm{R}$, we can list the expression of the length $\mathrm{L}$ of the generatrix of the cone according to the Pythagorean theorem:

$$
L^{2}=R^{2}+H^{2}
$$

The expression of cone side area can also be obtained:

$$
S=\pi R L
$$

By combining formula (1) with formula (2), we can get the exact value of the cone model correspond corresponding to each country.

In order to comprehensively consider the number of environmentally displaced persons caused by sea level rise, we have established a threat ratio $\varepsilon$ :

$$
\varepsilon \geq 1
$$

$\varepsilon$ is positively correlated with the number of people threatened by sea level rise, i.e., the greater the value of $\varepsilon$ is, the greater the area threatened by every millimeter of sea level rise, the more people become climate environmentally displaced persons.

According to the growth rate $\lambda$ of sea level and the past time $t$, we can establish the expression of dangerous height caused by sea level rise:

$$
h=\lambda \varepsilon t
$$

The rise of sea level is equivalent to that of intercepting the cone parallel to the cone ground, and the part that is still the cone is not submerged, while the truncated cone is the submerged part. According to the similarity of right triangle, we can get the relationship between the bus length of the new cone cut by sea level rise, the new height and the ground radius:

$$
\frac{H-h}{H}=\frac{r}{R}=\frac{l}{L}
$$

Through the area and threat coefficient of the sea-level inundation cone model, we can build the proportion coefficient of climate environmentally displaced persons caused by sea-level inundation countries:

$$
k=1-\frac{\pi r l}{\pi R L}
$$

Before the rise of sea level did not lead to the collapse of a country, the expression of the number of climate environmentally displaced persons caused by the rise of sea level in a country is as follows:

$$
n_{i}=k
$$

The expression of the number of environmentally displaced persons caused by sea level rise in the world's island countries over time is as follows:

$$
N=\sum_{i=1}^{n} n_{i}
$$


We have collected the data of the highest altitude, population and land area of 43 island countries in the world. Through computer programming (the rate of sea level rise is $3 \mathrm{ml} / \mathrm{A}$, and the threat coefficient is 10), we have obtained the charts of the change of the number of climate environmentally displaced persons in the next 100 years, 200 years, 500 years and 1000 years

\subsubsection{Results}

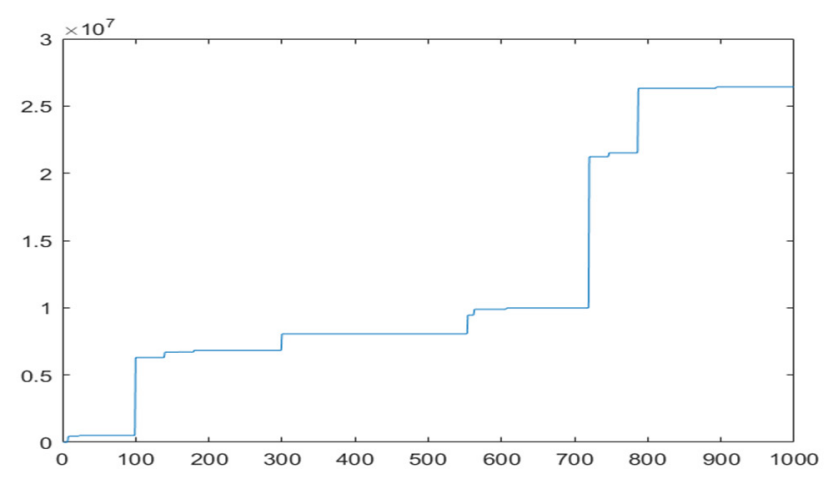

(a)

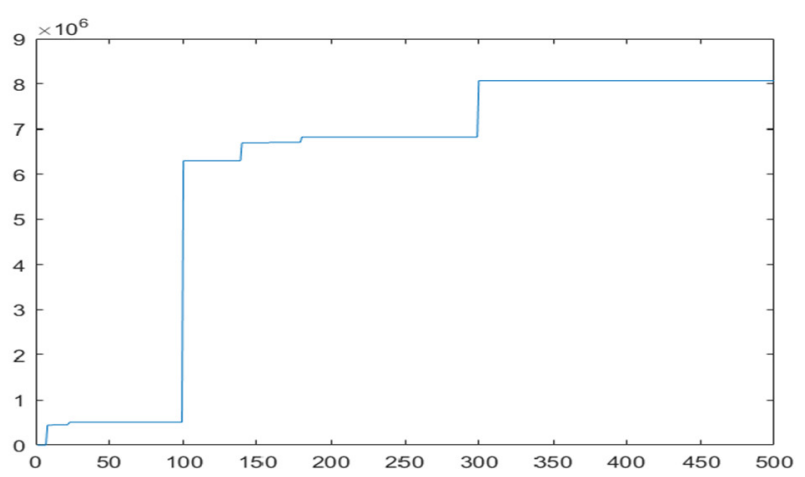

(b)

Figure 2. Number of environmentally displaced person generation in 1000 years (a)

Figure 3. Number of environmentally displaced person generation in 500 years (b)

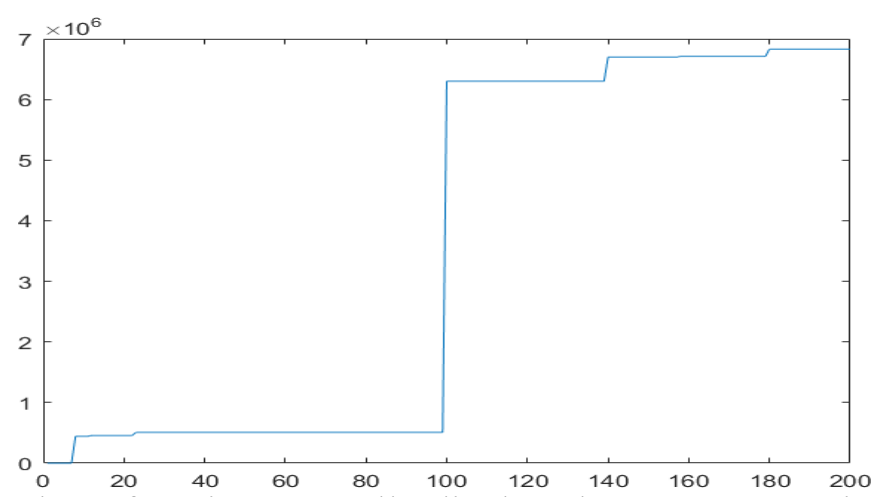

Figure 4. Number of environmentally displaced person generation in 200 years

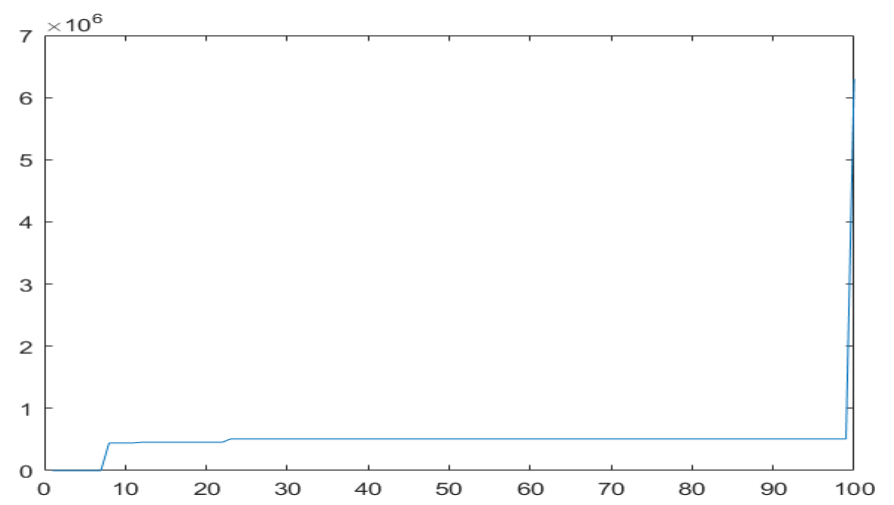

Figure 5. Number of environmentally displaced person generation in 100 years

It can be seen from the chart that the rise of sea level has a variability for the generation of climate environmentally displaced persons in island countries. According to the calculation of the model, in about eight years, all the citizens of Maldives will become climate environmentally displaced persons, and in 100 years, the number of climate environmentally displaced persons who are homeless due to the inundation of land by sea water will reach 6.3 million. In 200 years, it will reach 6.8 million. The specific population forecast is as follows: 
Volume 14 (2021)

Table 3. The number of environmentally displaced person born in the island with the change of time span

\begin{tabular}{|c|c|}
\hline Time passing (year) & $\begin{array}{c}\text { environmentally displaced persons caused by island countries } \\
\text { with rising sea level }\end{array}$ \\
\hline 100 & 6300638 \\
\hline 200 & 6829649 \\
\hline 300 & 064219 \\
\hline 500 & 8064219 \\
\hline 600 & 9886308 \\
\hline 800 & 26319244 \\
\hline 1000 & 26422294 \\
\hline
\end{tabular}

This is only an independent prediction model for the number of climate environmentally displaced persons on the island due to sea-level rise. Considering the impact of sea-level rise on the world, the number of climate environmentally displaced persons will increase greatly. According to the accurate prediction, the global environmentally displaced persons will reach 140 million to 1 billion in 2050 . In any case, those who lose their land need a place called home.

\subsubsection{Analysis of the Result}

(1) The results of the model show that it is urgent and difficult for human beings to solve the environmentally displaced person problem.

(2) By simplifying the sample data and the actual situation, this model accurately predicted the change of the number of climate refugees, and thus analyzed the scope of the environmentally displaced person problem from the number of people at risk, but did not specifically consider the cultural and topographic factors.

\section{Conclusions of the Problem}

The amount of environmentally displaced person produced by island countries as a result of sea level rise can change dramatically. After 100 years the number of environmentally displaced persons will be 6.3 million.

The main fault country of climate warming needs to assume the responsibility for the placement of environmentally displaced person. The choice of destination country is made by integrating the degree of cultural fit between the migrating country and the destination country and the acceptance degree of the destination country to environmentally displaced person. Taking Maldives as an example, after adopting the destination country decision model, the United States should provide 150,000 environmentally displaced persons from Maldives, Australia should provide 160,000 environmentally displaced persons from maldives, and Japan should provide nearly 130,000 environmentally displaced persons.

For the sake of human rights and cultural protection, we should try our best to respect the language choices and religious beliefs of environmentally displaced persons.

\section{References}

[1] Huang Mingwei. 3D reconstruction of material and cultural heritage based on multiple images [D]. Fuzhou University, 2016.

[2] Mao Yingjie. International law problems and Countermeasures in climate refugee protection [D]. East China University of political science and law, 2014.

[3] Current affairs: current affairs report for college students 2006 issue 46,1 page in total. 
[4] Fei Guangzheng 2001 Software Research Institute of Chinese Academy of Sciences: Computer Application Technology.

[5] Shen Nanyang: the social situation and Countermeasures in Germany under the background of "refugee crisis", Journal of Jiangsu No.2 Normal University, issue 4, 2019.

[6] A comprehensive study of religious multicultural integration between Guangxi and Southeast Asia under the background of the new Silk Road.

[7] Zhang Ke, Zhang Ke - Journal of Jining University, issue 1, 2019.

[8] He Shengbing, Zhu Yunliang: social adaptation strategies of disaster immigrants in the context of extreme climate change.

[9] Wu Xianhua, Wang Qian review on the research progress of climate migration.

[10] Meng Xianglin. Research on international law of climate refugees [D]. Heilongiiang University, 2019.

[11] Sun Zi Wei. Research on international climate migration [D]. East China Normal University, 2012. 